\title{
Culture as an environmental factor on the impact of intrapreneurship in engineering companies: Comparison of German and American engineering companies
}

\author{
Seray Toksöz ${ }^{1 *}$ \\ ${ }^{1}$ Istanbul Esenyurt University, Istanbul, Turkey
}

\begin{abstract}
The main aim of this study was to explore the extent to which intrapreneurship is taking place in engineering companies in the US and Germany. To serve this purpose, a deductive approach was followed, and a mixed methodology was employed in order to measure the perceptions about the existence of intrapreneurship in each country and to develop an understanding what factors have an effect on the concept among the engineering companies' employees. The data collection procedure included questionnaires which were carried out with the selected employees of the engineering companies. For the analysis of data obtained from the questionnaires, several statistical analyses were utilised, and SPSS software was used. To obtain the managements' views on the issue, interviews were conducted. Interviews were analysed through using narrative method. According to results, extent of the intrapreneurship perception among the US employees is higher compared to employees from Germany. Managements in both countries accepts the importance of intrapreneurship for their organisations however, it seems like there is a problem in flowing down these views to employees since employees especially in Germany believes otherwise. In this context, three main factors were determined in this study which can be counted as important factors which hinders the level of intrapreneurship in the US and Germany. These factors are lack of top management support, lack of communication and lack of adequate reward scheme within the organisations. In this study the role of culture in determining intrapreneurship behaviour within the organisations was also determined. In this context, it is believed that due to cultural differences between the US and Germany, employees do not perform intrapreneurship behaviour in Germany.
\end{abstract}

\section{Introduction}

The concept of corporate entrepreneurship (also called as intrapreneurship) as observed by Shaw, O'loughlin and Mcfadzean [1], is nowadays largely considered as a positive change in business perspective and in fact, it is an emerging field of research.

\footnotetext{
* Corresponding author: sry.gky@hotmail.com
} 
Gautam and Verma [2] argue intrapreneurship currently lacks a universally accepted definition. There is a diverse range of terms used to refer to the multifaceted notion of corporate entrepreneurship, including what Kuratko, Montagno and Hornsby [3] refer to as intrapreneurship; Schollhammer [4] refers to internal corporate entrepreneurship; Ellis and Taylor [5] refer to corporate ventures; Veciana [6] refers to venture management; Roberts [7] refers to new ventures and Burgelman [8] refers to internal corporate venturing.

Irrespective of the increasing amount of attention directed at intrapreneurship, there is a conspicuous lack of agreement regarding what it comprises also. According to Burgelman [8], the essence of intrapreneurship is the creation of new business by individuals within existing organisations. Burgelman [8] maintain intrapreneurship embodies the perpetual struggle encountered by large corporations for diversification and renewal using new resource combinations to survive and simultaneously change the operational business environment and the organisation.

Zahra [9] argues intrapreneurship is a process involving creation of new business within existing organisations to increase organisational profitability, improve competitive edge and/or enhance commercial strategic direction. Burgelman [8] utilises the notion of intrapreneurship as a process, arguing it is intended to expand the specialised expertise within an organisation and subsequent opportunities using new combinations of internal resources.

Consequently, intrapreneurship is organisational efforts to extend, enhance and expand competitive edge using innovations generated internally that result in significant changes to competitive balance or that result in creation of entirely new segments [10].

As it can be seen, innovation and ventures and strategic stress are composite aspects of intrapreneurship [10]. However, these aspects are both differentiated and related in creating new business and markets using strategic and innovative product, process, technology and administration resource combinations. Miller [11] argues the second aspect comprising intrapreneurship is activities involving the renewal of competitive advantage and risktaking to support organisational survival. Renewal is a multifaceted term that includes redefining business cases, restructuring organisations and introducing new systems for innovation at organisational level [10].

Kuratko, Montagno and Hornsby [3] argue there are a number of significant commercial issues driving the need for intrapreneurship. Miller and Friesen [12] claim this includes (1) marketplace changes, innovation and improvement to prevent shrinkage and stagnation; (2) weaknesses in conventional corporate management styles, systems and structures; (3) employee turnover resulting from innovation-oriented employees tiring of bureaucratic organisational structures.

Because of the explained needs, intrapreneurship became a very important issue within the business environment. The growing importance of intrapreneurship worldwide has given rise to studies conducted on this subject. However, not many studies were conducted to compare and contrast the perception of employees towards intrapreneurship between different countries as well as in the context of the sectors. Therefore, in this study, the aim is to discuss the establishment of intrapreneurship within different countries and within engineering companies.

Aim and Objectives: The main aim of this study is to identify the role of culture on the intrapreneurship efforts. Followings are the subobjectives of this study:

- To understand how intrapreneurship is stimulated from within a company.

- To identify cross-national differences influencing the climate promoting intrapreneurial efforts. 


\section{Literature}

\subsection{The Concept of intrapreneurship}

A firm engaged in this intrapreneurship process may be termed an entrepreneurial firm which, according to Miller [11], is a firm that takes novel as well as risky steps to market its products, and that has the nerve to take innovative initiatives to supersede its competitive firms. Watson's [13] definition of entrepreneurship is that it is the development of innovative and audacious steps taken by a firm in marketing its new products or services, which is in variance with the production or marketing steps taken by other firms.

Another definition of it is provided by Kao [14] whose standpoint is that entrepreneurship is the process a firm engages in to identify new vistas of opportunities in the business world and assess risk management accordingly. In Zahra's [15] view, intrapreneurship signifies organisational modification, a process that involves the following three variables: innovation, venturing and strategic renewal. Zahra and Pearce [16] describe entrepreneurship as a strategic change in the concept of business cherished by an organisation. This change in perspective aims at catering to the changing needs of customers and getting to a better competitive position in comparison with other organisations. Another definition is proposed by Covin and Slevin [17] who deem it as a process of developing an innovative strategic outlook of an organisation, which determines its entrepreneurial behaviour [18].

Intrapreneurship is utilised to raise the competitive spirit of companies involved in similar enterprises. It encourages organisations to develop new innovative products and services that can help create a special niche for them in the market. They can, thus, enhance the status the organisation holds in the market by offering value-created products. Figure 1 ahead illustrates the terms that are used for the entrepreneurial endeavours that take place within an organisation [19].

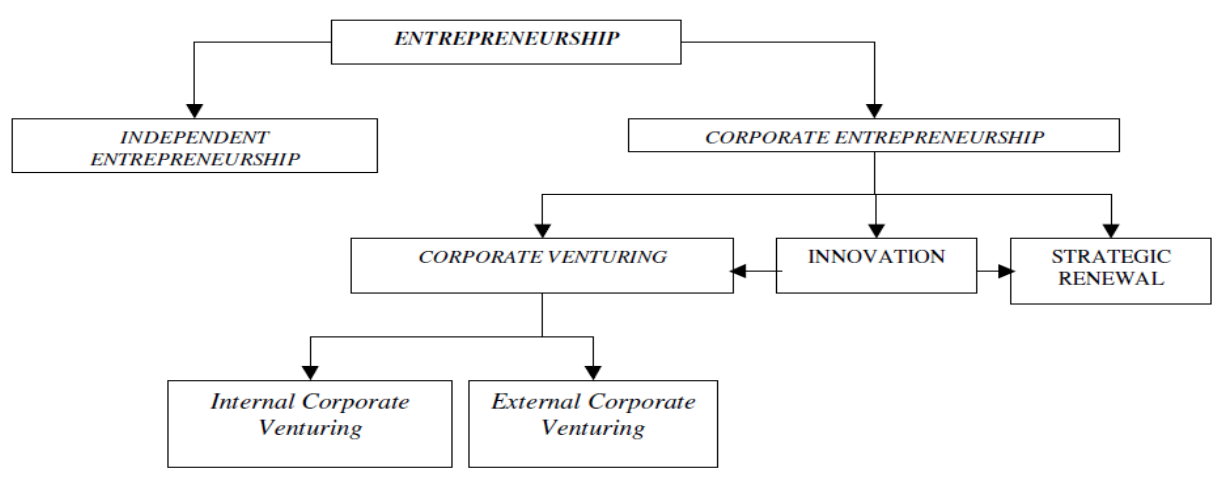

Fig. 1. Entrepreneurship. Source: Pizarro-Moreno, Real and Sousa-Ginel [19].

Despite differences, there are various terms within the definitions for intrapreneurship within literature. Some the terms include but are not limited to corporate venturing, internal corporate entrepreneurship as well as corporate entrepreneurship [20]. Intrapreneurship was introduced as terminology in 1985 by Pinchot who attempted to create a definition for entrepreneurship exercises within organisations. Studies regarding intrapreneurship are often linked to Pinchot's study in 1985. Pinchot [21] defines intrapreneurship as the ability of employees to take initiative in order innovative solutions within the organisation. Eckhardt and Shane [22] define an intrapreneur as a corporate entrepreneur that allows entrepreneurship to thrive within an organisation. Kuratko, Covin and Garrett's [20] study 
highlights that in order for entrepreneurship to exist within the organisation, the organisation should be a larger corporate as opposed to a small business.

Narayanan, Yang and Zahra [23] define an intrapreneur as an individual within a larger organisation that actively takes innovate actions towards his or her responsibilities that at time may be risky to ultimately create a profitable notion or end-good; hence, an intrapreneur is often seen as one that envisages a route to create a real and valuable result from an idea. An intrapreneur is also seen as one who enthusiastic about new responsibilities and opportunities so as to generate an inspired difference. Employees are therefore able to be intrapreneurs in their current roles without having to leave their job. For intrapreneurship to be sustainable it is advised that start-ups are launched steadily. Hence, in order to maximise the efficiency of resources, intrapreneurs within an organisation are suggested to be given independence increasingly over time [23].

Fry's [24] definition of intrapreneurship is similar to the previous definitions and it also points out that it is the process which allows creative products to be developed due to an entrepreneurial corporate culture in the organisation. The relevance of innovativeness is further highlighted by Garvin and Levesque [25] as they argue it is the key instrument in forming profitable ideas and products through speeding change and creating more opportunities to share the skills of intrapreneurs.

Intrapreneurship is said to be a result of corporate initiatives which encourage employee participation and show an active effort to inspire entrepreneurial activities in the company. These efforts will then allow the company to produce new products are acquire them and also administer the procedure for innovations. Corporate or individual entrepreneurship often takes place in existing and developed companies. These companies offer support for developing and utilising innovations which are considered to be beneficial both economically and strategically while also being in line with the company's objectives [10]. Innovative actions may be in the form of developing an existing product, reducing costs, reengineering, identifying untouched markets, applying existing products or services in a new way or new initiatives. These initiatives differ from mundane marketing and product development initiatives of companies that are within the structure and procedures of a company [26]. Intrapreneurship's basis and aims can be seen in relation to its competitive positioning in the market which essentially reflects the company's competitive strategy. Untouched resources for innovation may be utilised in every section of traditional corporate constitution. Procedures under intrapreneurship usually take a bottom to top approach which creates company loyalty and enthusiasm for innovative procedures. Entrepreneurship initiatives within a company are the result of a collective and mutual effort from innovative individuals [10].

A group of individuals with corresponding useful skills and characteristics are required as well as a group that is truly dedicated and lead by an inspiring leader to achieve company objectives [25]. Focusing more on group development as opposed to individual improvement as well as being in line with company limitations is also a characteristic of these programs [26].

In addition to the descriptions above, intrapreneurship may also be considered as the procedure where new skills are created [19]. Based on this idea, the procedure is maintained three key factors as observed below in Figure 2.

Intrapreneurship initiatives may take place both externally and internally. The internal initiatives are characterised by developing internal markets within a large institution creating smaller sovereign groups to generate testable markets or develop and improve innovation services for employees as well as improve technology and production techniques of a company [10]. Such activities could include innovation surround procedure, administration and products in many levels of a company [9]. 


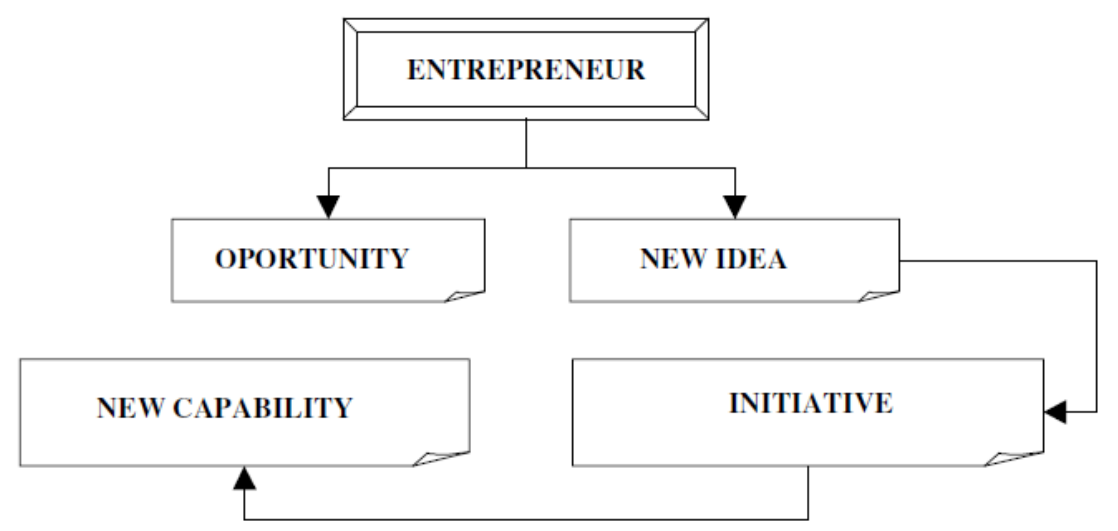

Fig. 2. Basic Elements of Intrapreneurship.Source: Pizarro-Moreno, Real and Sousa-Ginel [19].

Intrapreneurship is stated to take form in various strategies including administrative (managing R\&D), opportunistic (seeking and utilising opportunities), imitative (making an external development internal either by technology or company strategies), acquisitive (mergers and acquisitions and divestments) as well as incubators (creating semiindependent groups within a company) [22].

External intrapreneurship is regarded as the initial action that combines resources within an environment with the resources of an individual entrepreneur to create a new and unique combination of resources. External initiatives may be in the form of corporate venturing, supporting ventures, joint ventures, M\&As, by-products or other forms [26].

Intrapreneurship may take place as a formal or informal initiative that may focus on external or internal elements. Informal initiatives may take place irrespective of the company's approval. These efforts may be stemmed by an individual's innovation or selfinterest initiative. At times, these initiations may be appreciated and adopted by the company, transforming it into a formal process that is a central part of business operations [27]. Regardless of where it is exercised, the sole purpose of intrapreneurship is to improve a company's competitive stance as well as economic position [28]. Irrespective of the diversity of language used in the definitions above, there is a common thread that linking the efforts to define a single phenomenon. The common thread is the referral of the definitions to activities occurring within the context of an established organisation that represent efforts to define entrepreneurial activities that extend throughout organisational systems. Such entrepreneurial initiatives are executed at organisational level rather than at individual level and are characterised by organisational level support [29].

\subsection{Model of intrapreneurship}

There have been a number of studies regarding the formation for a theory of intrapreneurship. Zahra's [9] study created a model, which was also tested, for intrapreneurship that was founded on three variables: organisational, strategic and environmental. Similarly, Russell and Russell's [30] study suggested a verified model for intrapreneurship which was based on cultural, structural, environmental and strategic variables. An interactive model was introduced by Desouza [31] who demonstrated that intraprenuerism varies depending on organisational and individual variables. A comprehensive study by Covin and Slevin [17] is a milestone in intrapreneurship literature. The model they suggest was formed based on organisational and strategic variables and their relation to overall company performance. The variables they used were: 
entrepreneurial position, external factors (manufacturing and environmental), internal factors (organisational and cultural) and strategic (company objectives and strategy).

A comprehensive model for intrapreneruship should give an idea on the process of how innovative ideas are generated and carried out and how creativity supporting actions act as a key element in the establishment of intrapreneurism [32].

Guth and Ginsberg [33] use previous models for strategic management as their starting point to develop a model for intrapreneurship that shows a theoretical framework that can be further used in strategic management. The model presented five modules for intrapreneurship which were: the influence of environmental factors, the influence of strategic managers, organisational factors, organisational structure and culture and the overall effect of intrapreneurism on company performance [33].

Environmental factors that Guth and Ginsberg [33] looked at sever environmental changes like deregulation. They also looked at how environmental factors could shift strategies in a distinct and less generic way. The study suggested that a more active and aggressive environments would lead to more entrepreneurial behaviour from companies. They also state that industrial form is a factor in the successfulness in developing new products. Therefore, competitiveness in the market and technological foundation have an evident effect on intrapreneurship. Technological development within an organisation or the commercialisation of technologies created by other companies form the foundation for the development of new services and products. As all companies seek innovation, a very competitive environment is created whereby each company seeks to discover new products or mix of products to give their company a competitive edge.

Regarding strategic leaders' influence to intrapreneurship, Guth and Ginsberg [33] state that the upper management's form of managing has an impact on the degree and outcome of new business ventures. They add that mid-level managers act as a bridge between upper management and staff whereby they influence the level of success in implementing the idea. Some may state that intrapreneurial behaviour in companies is greatly related to the views and values of strategy forming leaders in the company.

Guth and Ginsberg [33] discuss that companies which follow acquisition focused strategies have relatively less research and development compared to companies which follow strategies for internal development through innovative actions. Furthermore, they discuss that new business initiatives do not have an effect on the sales amount of new services or products. A company's strategic stance therefore affects its innovative degree.

It is discussed that company strategies that focus on expanding market share tend to better integrate innovative entrepreneurial initiatives [34]. The entrepreneurial stances of organisations are also discussed to be reflective of its strategic stance on operative issues of a company. Regarding company performance's effect on intrapreneurship, Guth and Ginsberg [33] discuss that companies that are regarded as being successful make us of innovative product and procedure innovations. A key issue for companies and innovation is that often companies will approach new innovations only after the company has been in a systematic decline and upper management has changed. Innovation and relevant change within a company may only occur if and when the company has an abundance of resources which may be used to make use of opportunities and tackle external pressures or internal disasters [27]. Regarding the positive effect of intrapreneurism on company performance, Guth and Ginsberg [33] define three factors. Firstly, the extent of new products introduced affects the performance of the company. Secondly, start-ups with venture support that are independent obtain higher profitability much faster than corporate start-ups. Finally, products that enter first into the market have an advantage to determine positive performance. 


\section{Methodology}

The main aim of this study is to identify the role of culture on the intrapreneurship efforts. For the purposes of this research project, a realist approach was adopted. In fact, the philosophical framework of realism was used during the data collection and analysis part of this study. In this research, a deductive approach was also adopted. In this context, first theories were identified and then the questions to be asked to employees and managers were determined. The approach has been elaborated by Easterby-Smith, Thorpe and Jackson [35] as "combining more than one method, such as a questionnaire survey and interviews, where both assume similar importance in the study". In this study, mixed method was used. In doing this, quantitative data was collected through questionnaire and qualitative data was collected through interviews.

In this study, questionnaire method was used to determine research data from the employees. 50 engineering companies' employees from each country (Germany and the US) were selected and the questionnaires were filled by the selected respondents. In collecting the data, The Corporate Entrepreneurship Climate Instrument (CEAI) was used to evaluate the five important factors that impact intrapreneurship, organizational boundaries work discretion/autonomy, rewards/reinforcement, time availability, management support and organizational boundaries [36]. As elaborated by Hornsby, Kuratko and Zahra [36] the "instrument used to empirically identify the internal conditions in corporate entrepreneurship activities". In this survey 5-point Likert scale was used and it is considered that highest the score better the intrapreneurship environment in the company.

Survey conducted online by asking employees to fill the questionnaire online and then send the link to people who they know and work in engineering companies. Therefore, snowball sampling method was used, and the number 50 was determined to reach. The aim of conducting the questionnaire was identifying the extent of intrapreneurship in engineering companies in both Germany and the US.

To obtain the management views, interview was conducted. 2 interviewees from each country were selected to determine the managements' views on the subject. The Author has built professional relationships all over the world. Therefore, qualitative data was collected from the engineering sectors in Germany and the USA through network.

Qualitative research was conducted in the form of telephone interviews with a sample size of 4 individuals at leading positions in the US and Germany ( 2 from each country), in order to gather primary data. The structure of the interview was semi-structured, enabling the interviewee to express their own experience and point of view on the topic. The critical incident approach was applied, asking the responded to think about a situation where he/she has been confronted with intrapreneurship, mostly expecting data from a positive and negative experience. The interviewees were encouraged to explain the incident in detail to discover the impact of intrapreneurship. Each interview was lasted around 30 minutes and the interviewer took notes during the interview. For the qualitative analysis, narrative approach was used. Therefore, only relevant information that are given by the interviewed managers were included in the analysis.

In this study, SPSS 25.0 programme was used to determine the quantitative results. In this context, questionnaire results were analysed. In this analysis, first of all demographic characteristics of the respondents were presented through using frequency analysis. Following to this, intrapreneurship extent of the employees were determined through using "mean, median, standard deviation". Reliability of the questionnaire was determined by using Cronbach alpha test. Finally, the results obtained from both countries compared and contrasted. 


\section{Analysis}

\subsection{Interview analysis}

\subsubsection{Interviews - Germany}

According to the interviewees, nowadays, there is a wind of change in the management of companies in Germany where more freedom is given to regional offices in order to make them autonomous. However, according to the interviewees in Germany intrapreneurship is only applied and allowed at a certain level within the organisations despite its importance. For instance, corporate entrepreneurship exists in the top management in the form of innovation and modernisation projects which involve a certain degree of entrepreneurship. However, risk tolerance is relatively low. Eesley and Longnecker [37] carried out a study which looks at the barriers of achieving intrapreneurship and proposed that one of the barriers in front of intrapreneurship is lack of encouragement towards risk taking. Therefore, it can be said that in Germany there is a barrier related to risk tolerance which should be eliminated.

One of the interviewees claimed that changing the mentality which views entrepreneurship as a taboo cannot be achieved overnight. In fact, it is believed by the interviewees that it will take years of innovation and modernisation works before an average employee at engineering companies realises that entrepreneurship is the driving force for change. However, interviewees also claimed that the promising fact is that engineering companies has several attributes which foster intrapreneurship. For instance, supporting enthusiasm of employees and empowerment are among the main characteristics. In addition, companies encourage innovativeness and creativity of employees to some extent. On the other hand, according to the interviewees, it is hard to say that proactiveness is a common attribute existing at engineering companies in Germany. Last but not least, it is not certain whether their companies have organisational flexibility and risk-taking characteristics. Despite the absence of important attributes like proactiveness and flexibility, the interviewees believed that the current management system promotes and supports intrapreneurship at some extent in their companies. However, in the literature, it was claimed that a key role is played by the board of directors and the management in developing an atmosphere of intrapreneurship in an organisation [38].

Therefore, flexibility should be provided within the organisation. In this context, it can be said that working environments that do not provide flexibility and freedom to their employees could hinder intrapreneurial behaviour within a company [21]. According to interviewees, there is a shift in the country towards a motivational institutional management system where employees are motivated with financial incentives. In this process, according to the interviewees, Human Resources (HR) practices have become prominent because improving the competitiveness of their companies in the country depends on the development of ameliorating the salary system, which would provide the necessary financial incentives for employees.

According to the interviewees in order to determine the good work environment which fosters intrapreneurship in engineering companies, practices related to the reward and payment, job rotation, training and career development are very important. According to the interviewees, the size of the country as a whole offers the great advantage for job rotation. As a part of the development process, high priority is given to implementing a high degree of job rotation for management personnel. This is because it is well-recognised by top management that job rotation is of great importance to improve the job skills of employees. 
Specialists are sent to different regions to enable knowledge and experience transfer, even though some posts and tasks require qualified workers, which demands formation in specific fields and job experience. By doing this the interviewees believe that employees can find a new thinking in new areas and thus intrapreneurship can be boost. The interviewees also accepted the importance of the reward scheme within the organisations. In order to promote intrapreneurship in engineering companies, they have number of bonus and award schemes. At central offices and remotely located regions a special regulation has been created; this regulation comprises the aspect of bonus payments for general workers, specialists, heads of departments and regional directors etc. and is based on the relation between pro-activeness and current needs, as well as the size of the promotion or bonus and the extent to which those needs were met. Bonuses are paid for proactiveness and high achievements which ensure production cost reductions and revenue growth, improvement of the quality of work, labour effectiveness etc. In the case of training, engineering companies provide training programmes for all of its employees. In the case of career development, it takes three or four years on average for an employee to get to the next level. However, the interviewees admitted that there is no clear direction on what basis employees are evaluated. This is because engineering incorporates numerous jobs and operates in different regions which have different requirements, needs and workloads. For instance, in some cases moving up the career ladder takes longer for some employees, but it is possible for a person to become the managing director of a regional department very quick. Such career advancement may take 50 years or more but there are some cases where employees have been promoted from an engineer position to a head of department within a year.

Findings from Germany indicates that intrapreneurship is not at its best extent since there are several issues such as inflexibility and avoiding risk taking. However, intrapreneurship is developed with favourable business conditions that assist the development and growth of entrepreneurs within the organisation. Such a corporate conditions would create impacting strategies that sustain the entrepreneurs' passion and development [39].

\subsubsection{Interviews - US}

It is admitted by the interviewees that intrapreneurship is an essential part of the development of large corporations, so as to improve competitiveness and the moral aspect of introducing something useful for society because large corporations have resources and facilities to bring about changes. Both interviewees agreed that corporate entrepreneurs play a significant role in the future of the companies in that their projects and successful start-ups may lead to some new spin-offs which could create an entirely new business and thus a new income stream. In terms of the factors which influence the development of corporate entrepreneurship, regarding failures and mistakes as part of the learning process and cost reduction is found to be most important. It is advocated by the interviewees that these failures and mistakes should be considered as innovative ways of improving efficiency at different levels, in other words maximum achievements with minimum resources spent. Considering that the goal is to improve efficiency while reducing costs, proactiveness and resourcefulness are important qualities for the development of intrapreneurship. According to the interviewees, this does not necessarily mean that companies must produce their own high-tech equipment; they can collaborate with other companies. Buekens [40] investigates how intrapreneurship can be promoted, focusing on how leaders must evolve by lowering barriers to create a supportive environment. The author Buekens [40] identifies a variety of obstacles which can hinder the intrapreneurial performance, such as the present of dominant entrepreneurs, a limited holistic perspective, 
and an insufficient information flow to executive staff members. In order to foster intrapreneurship, leaders have to reduce the level of bureaucracy and establish an environment where failure is acceptable. Therefore, it can be said that intrapreneurship can be better understood in US engineering companies.

According to interviewees, intrapreneurship is important from the engineering companies' perspective since it helps both to organisation and society. According to the interviewees, it helps in organisation to perform better and increase its competitiveness. In societal way, intrapreneurship in engineering companies enables governments and society to move forward in modernity as well as reduction of costs, environmental damage and etc. therefore according to the interviewees intrapreneurship should also be seen as an corporate social responsibility by the engineering firms. In fact, according to the interviewees, engineering companies has always made major contributions to the development of infrastructure and thus to the development of both residential and industrial centres. Therefore, intrapreneurship focused on innovation and modernisation is a prerequisite for the development of infrastructure. The same principle applies to other large companies in the sense that intrapreneurship is being implemented at different levels so it is also socially very important to improve the country's wellbeing. For this reason, company projects which provide benefits for society are rewarded by reducing taxation or facilitating access to capital.

\subsection{Questionnaire analysis}

The Corporate Entrepreneurship Climate Instrument (CEAI) was used to evaluate the five important factors that impact intrapreneurship, organizational boundaries work discretion/autonomy, rewards/reinforcement, time availability, management support and organizational boundaries. As elaborated by Hornsby, Kuratko and Zahra [36] the "instrument used to empirically identify the internal conditions in corporate entrepreneurship activities". In this survey 5-point Likert scale was used and it is considered that highest the score better the intrapreneurship environment in the company.

\subsubsection{Demographic characteristics of the respondents}

Table 1. Demographic characteristics of the respondents.

\begin{tabular}{|l|l|c|c|}
\hline \multirow{2}{*}{\multicolumn{2}{|c|}{}} & \multicolumn{2}{|c|}{$\%$} \\
\cline { 3 - 4 } Gender & Male & US & GERMANY \\
\cline { 2 - 4 } & Female & $78 \%$ & $72 \%$ \\
\hline \multirow{4}{*}{ Age } & $18-29$ years old & $22 \%$ & $28 \%$ \\
\cline { 2 - 4 } & $30-49$ years old & $20 \%$ & $30 \%$ \\
\cline { 2 - 4 } & $50-64$ years old & $48 \%$ & $36 \%$ \\
\cline { 2 - 4 } & 65 years and over & $28 \%$ & $32 \%$ \\
\hline \multirow{4}{*}{ Education } & some high school & $4 \%$ & $2 \%$ \\
\cline { 2 - 4 } & high school graduate & $8 \%$ & $6 \%$ \\
\cline { 2 - 4 } & some college & $30 \%$ & $2 \%$ \\
\cline { 2 - 4 } & trade/technical/vocational training & $8 \%$ & $12 \%$ \\
\cline { 2 - 4 } & college graduate & $6 \%$ & $28 \%$ \\
\cline { 2 - 4 } & some postgraduate work & $6 \%$ & $30 \%$ \\
\cline { 2 - 4 } & post graduate degree & $28 \%$ & $12 \%$ \\
\hline \multirow{4}{*}{$\begin{array}{c}\text { Company } \\
\text { size }\end{array}$} & $1-49$ & $48 \%$ & $10 \%$ \\
\cline { 2 - 4 } & $50-999$ & $14 \%$ & $38 \%$ \\
\cline { 2 - 4 } & $1,000-4,999$ & & \\
\hline
\end{tabular}




\begin{tabular}{|l|l|c|c|}
\hline \multirow{3}{*}{ Job Level } & 5,000 or more & $6 \%$ & $4 \%$ \\
\cline { 2 - 3 } & Intern & $2 \%$ & $2 \%$ \\
\cline { 2 - 3 } & Entry Level & $6 \%$ & $12 \%$ \\
\cline { 2 - 3 } & Analyst / Associate & $6 \%$ & $10 \%$ \\
\cline { 2 - 3 } & Manager & $18 \%$ & $24 \%$ \\
\cline { 2 - 4 } & Senior Manager & $12 \%$ & $18 \%$ \\
\cline { 2 - 4 } & Director & $8 \%$ & $8 \%$ \\
\cline { 2 - 4 } & Vice President & $10 \%$ & $8 \%$ \\
\cline { 2 - 4 } & Senior Vice President & $6 \%$ & $4 \%$ \\
\cline { 2 - 4 } & C level executive (CIO, CTO, COO, CMO, Etc) & $16 \%$ & $4 \%$ \\
\cline { 2 - 4 } & President or CEO & $8 \%$ & $6 \%$ \\
\cline { 2 - 4 } & Owner & $8 \%$ & $4 \%$ \\
\hline
\end{tabular}

\subsubsection{Comparison of the US and German employees}

Table 2. Comparison of the US and German employees.

\begin{tabular}{|l|c|c|}
\hline \multicolumn{1}{|c|}{ Section } & \multicolumn{2}{c|}{ Mean } \\
\cline { 2 - 3 } & US & Germany \\
\hline Section 1: Management support for corporate entrepreneurship & 3.62 & 2.72 \\
\hline Section 2: Work discretion & 3.81 & 3.15 \\
\hline Section 3: Rewards/Reinforcement & 3.27 & 2.90 \\
\hline Section 4: Time availability & 4.09 & 2.86 \\
\hline Section 5: Organizational boundaries & 4.10 & 2.90 \\
\hline \multicolumn{1}{|c|}{ Overall Score } & $\mathbf{3 . 7 5}$ & $\mathbf{2 . 8 8}$ \\
\hline
\end{tabular}

As it can be seen from the above table, intrapreneurship behaviour is highly promoted in engineering companies in the US compared to Germany. This shows that culture plays a critical role in determining intrapreneurship behaviour within the organisation as well as promoting intrapreneurship within the organisation. In fact, German employees does not like uncertain working environment which gives freedom and flexibility compared to employees and managers in the US. Similarly, employees in the US are more individualistic compared to German employees and managers and therefore, they can perform better individual intrapreneurship behaviour compared to the employees in Germany.

According to Zahra and Garvis [41], there is a positive relationship between intrapreneurship and financial outcomes. Therefore, it can be expected from engineering companies in the US to perform better financially compared to ones in Germany. Differently, Sathe [42] argues that it is crucial to survival for an organisation to establish an environment that fosters intrapreneurship at the employee level to promote innovation and generation of new goods, services and markets. Therefore, it can be expected from engineering companies in the US to be more innovative compared to ones in Germany.

In the literature, Lumpkin and Dess [43] proposed that the process of encouraging entrepreneurial activities with an organisation results in an increase in organisational commitment to innovation, which in turn leads to improvements in financial returns. Accordingly, it was found in this study that loyalty among the US employees higher compared to German ones. Therefore, it can be said that intrapreneurship increases the loyalty and loyalty may lead innovativeness and better financial results.

Consequently, in the literature it was claimed that corporate managements actively seek innovation and fresh ways in which to promote and develop intrapreneurship both as a source of competitive edge and to improve financial results [43]. Therefore, it can be said that intrapreneurship should be foster in both US and the Germany in order to create better environment for the innovation which leads better financial performance. 
Tourigny and Le [44] to identify the barriers faced by Canadian manufacturers while pursuing innovation which revealed that more than half $(58 \%)$ the respondents thought that the company did not have sufficient staff or resources to initiate new products and services as the existing employees were occupied with ongoing production. Another notable factor that creates a hurdle in implementing entrepreneurship in a company is the prevalent perception among employees about business meetings not being productive. No follow-up of the decisions taken at meetings is also perceived as a barrier by employees [45]. In this study communication, management support and reward scheme were found as rather important in fostering intrapreneurship behaviour within the engineering companies.

Kocjancic and Bojnec [46] investigated how intrapreneurship impacts the efficiency and competitive positions of large companies in Slovenia. The research illustrates that many companies where already aware of the potential provided by intrapreneurship and have already been profiting from its potential [46]. However, in this study, situation was found as otherwise since employees' perception was not good in both countries.

\section{Conclusion}

According to results, extent of the intrapreneurship perception among the US employees is higher compared to employees from Germany. Managements in both countries accepts the importance of intrapreneurship for their organisations however, it seems like there is a problem in flowing down these views to employees since employees especially in Germany believes otherwise. In this context, three main factors were determined in this study which can be counted as important factors which hinders the level of intrapreneurship in the US and Germany. These factors are lack of top management support, lack of communication and lack of adequate reward scheme within the organisations. In this study the role of culture in determining intrapreneurship behaviour within the organisations was also determined. In this context, it is believed that due to cultural differences between the US and Germany, employees do not perform intrapreneurship behaviour in Germany.

It was also understood from the findings of this study that fostered intrapreneurship increases the employee performance then overall organisational performance. Increased overall organisational performance increases the overall country's economy by providing more input, decreasing unemployment level, creating value and etc. Increased country's wealth also increases the global economic welfare. The importance of intrapreneurship for global economy was also determined from the interviews. According to interviewees, intrapreneurship is important from the engineering companies perspective since it helps both to organisation and society. According to the interviewees it helps in organisation to perform better and increase its competitiveness. In societal way, intrapreneurship in engineering companies enables governments and society to move forward in modernity as well as reduction of costs, environmental damage and etc. therefore according to the interviewees intrapreneurship should also be seen as an corporate social responsibility by the engineering firms. In fact, according to the interviewees engineering companies has always made major contributions to the development of infrastructure and thus to the development of both residential and industrial centres. Therefore, intrapreneurship focused on innovation and modernisation is a prerequisite for the development of infrastructure. In this context, it can be said that intrapreneurship in engineering companies plays an important role for the global economy.

In this study it was also found that intrapreneurship cannot take place unless supported by the top management and the shareholders. The support may come in the form of different incentives offered to employees, who then put forth their best efforts for the success of the organisation's projects. This practice helps especially in the success of longstanding, full-of-risk, projects, which require consistent effort and patience. Thus, a key 
role is played by the board of directors and the management in developing an atmosphere of intrapreneurship in an organisation. Furthermore, having employees with entrepreneurial interest and skills is the backbone for companies to establish and carry out their corporate initiatives, without it intrapreneurism cannot take place. In this perspective, necessary trainings should be given to the employees. Next, intrapreneurship behaviour should be rewarded adequately so that employees try to be more innovative. Decreased bureaucracy and increased flexibility within the organisation should also be fostered by the management as well as allocating more time for the employees to become intrapreneurs. In this communication is also very important.

In this study, it was also found that intrapreneurship behaviour is highly promoted in engineering companies in the US compared to Germany. This shows that culture plays a critical role in determining intrapreneurship behaviour within the organisation as well as promoting intrapreneurship within the organisation. In fact, German employees does not like uncertain working environment which gives freedom and flexibility compared to employees and managers in the US. Similarly, employees in the US are more individualistic compared to German employees and managers and therefore, they can perform better individual intrapreneurship behaviour compared to the employees in Germany.

\section{References}

1. E. Shaw, A. O’loughlin, E. Mcfadzean, European Journal of Innovation Management, 8, 4, 393-408 (2005)

2. V. Gautam, V. Verma, The Journal of Entrepreneurship, 6, 2, 233-247 (1997)

3. D.F. Kuratko, R.V. Montagno, J.S. Hornsby, Strategic Management Journal, 11, 49-58 (1990)

4. H. Schollhammer, In: C.A. Kent, D.L. Sexton, K.H. Vesper, (eds.). Encyclopedia of entrepreneurship (Prentice-Hall, Englewood Cliffs, 1982)

5. R.J. Ellis, N. Taylor, Frontiers of Entrepreneurship Research, 527-542 (1987)

6. J. Veciana, Economia Industrial, 310/IV. (1996)

7. E.B. Roberts, Harvard Business Review, 58, 4, 134-142 (1980)

8. R.A. Burgelman, California Management Review, 26, 154-166 (1984)

9. S.A. Zahra, Journal of Business Venturing, 6, 4, 259-285 (1991)

10. P.K. Wong, Y.P. Ho, E. Autio, Small Business Economics, 24, 3, 335-350 (2005)

11. D. Miller, Management Science, 29, 770-791 (1983)

12. D. Miller, P.H. Friesen, Strategic Management Journal, 3, 1, 1-25 (1982)

13. T. Watson, International Small Business Journal, 13, 2, 34-46 (1995)

14. J. Kao, Entrepreneurial organization (Prentice-Hall, London, 1992)

15. S.A. Zahra, Journal of Business Venturing, 8, 4, 319-340 (1993)

16. S.A. Zahra, J.A. Pearce, Entrepreneurship, Innovation and Change, 3, 1, 31-45 (1994)

17. J.G. Covin, D.P. Slevin, Entrepreneurship Theory and Practice, 16, 1, 7-25 (1991)

18. T. Lau, K.F. Chan, S.H.C. Tai, D.K.C. Ng, Management Research Review, 33, 1, 6-22 (2010)

19. I. Pizarro-Moreno, J.C. Real, E. Sousa-Ginel, Corporate entrepreneurship: Building a knowledge-based view of the firm. Universidad Pablo Olavide, May (2007)

20. D.F. Kuratko, J.G. Covin, R.P. Garrett, Business Horizons, 52, 5, 459-467 (2009) 
21. G. Pinchot, Intrapreneuring: why you don't have to leave the corporation to become an entrepreneur. (Harper \& Row, New York, 1985)

22. J.T. Eckhardt, S.A. Shane, Journal of Management, 29, 3, 333-349 (2003)

23. V.K. Narayanan, Y. Yang, S.A. Zahra, Research Policy, 38, 1, 58-76 (2009)

24. F.L. Fry, Entrepreneurship: a planning approach. (West Publishing Company, Minneapolis, 1993)

25. D.A. Garvin, L.C. Levesque, Harvard Business Review, 84, 10, 102-112 (2006)

26. P.H. Phan, M. Wright, D. Ucbasaran, W.L. Tan, Journal of Business Venturing, 24, 3, 197-205 (2009)

27. F.W. Kellermanns, K.A. Eddleston, Entrepreneurship Theory and Practice, 30, 6, 809830 (2006)

28. R.D. Ireland, J.G. Covin, D.F. Kuratko, Entrepreneurship Theory and Practice, 33, 1, 19-46 (2009)

29. D.B. Audretsch, M.C. Keilbach, E.E. Lehmann, Entrepreneurship and economic growth. (Oxford University Press, Oxford, 2006)

30. R.D. Russell, C.J. Russell, Journal of Management, 18, 4 (1992)

31. K.C. Desouza, Intrapreneurship: managing ideas within your organization. (University of Toronto Press, Toronto, 2011)

32. H.E. Haller, Intrapreneurship: ignite innovation for escalating and enduring success: the secret to success!. (Silver Eagle Press, Idaho, 2014)

33. W.D. Guth, A. Ginsberg, Strategic Management Journal, 11, 5-15 (1990)

34. D.F. Kuratko, Entrepreneurship: theory, process, and practice. (Cengage Learning, Boston, 2016)

35. M. Easterby-Smith, R. Thorpe, P. Jackson, Management research. (Sage, London, 2012)

36. J. Hornsby, D. Kuratko, S. Zahra, Journal of Business Venturing, 17, 253-273 (2002)

37. D. Eesley, C. Longenecker, Industrial Management, 48, 1, 18-23 (2006)

38. J. Chen, Z. Zhu, W. Anquan, International Journal of Manpower, 26, 6, 529-543 (2005)

39. C.K. Volkmann, K.O. Tokarski, M. Grunhagen, Entrepreneurship in a European perspective: concepts for the creation and growth of new ventures. (Springer, Gabler, 2010)

40. W. Buekens, Procedia Economics and Finance, 16, 580-586 (2014)

41. S.A. Zahra, D.M. Garvis, J Bus Ventur, 15, 5/6, 469-493 (2000).

42. V. Sathe, Corporate entrepreneurship: top managers and new business creation. (Cambridge University Press, Cambridge, 2003)

43. G.T. Lumpkin, G.G. Dess, Academy of Management Review, 21, 1, 135-172 (1996)

44. D. Tourigny, C.D. Le, Economics of Innovation and New Technology, 13, 3, 217-250 (2004)

45. R. Kannan-Narasimhan, E.G. Flamholtz, Silicon Valley Review for Global Entrepreneurship Research, 2, 1, 4-24 (2006)

46. J. Kocjancic, S. Bojnec, Managing Global Transitions, 11, 2, 161-179 (2013) 